ISSN: 1679-3013

D.O.I.: 10.5914/to.2011.0074

\title{
CRIAÇÃO EXPERIMENTAL DA OSTRA-DO-MANGUE Crassostrea rhizophorae (GUILDING, 1828) EM BARRA DE SÃO MIGUEL, ALAGOAS.
}

\author{
Thiago Cabral VILAR ${ }^{1}$
}

Deusinete de Oliveira TENÓRIO ${ }^{1}$

Fernando Antônio do Nascimento FEITOSA ${ }^{1}$

Recebido em: 23/01/2012

Aceito em: $18 / 10 / 2012$

\section{RESUMO}

A criação de ostras no Brasil se iniciou em 1970, mas atualmente encontra-se concentrada principalmente na região Sul, sobretudo, baseada na criação da ostra japonesa Crassostrea gigas (Thunberg, 1793). Este estudo teve objetivo de avaliar o potencial de criação da ostra nativa Crassostrea rhizophorae (Guilding, 1828) e verificar as variáveis ambientais que mais influenciam seu desenvolvimento. As "sementes" utilizadas na criação foram coletadas em ambiente natural e o experimento teve duração de sete meses, entre fevereiro e agosto de 2011. O sistema de cultivo empregado do tipo fixo-suspenso, na zona entremarés do estuário do rio São Miguel. $O$ regime de chuvas, a salinidade e a temperatura foram os fatores que exerceram maior influência sobre o desenvolvimento das ostras. A salinidade apresentou forte correlação positiva com a taxa de crescimento mensal $\left(R^{2}=0,67\right)$ e a temperatura forte correlação negativa com os parâmetros de comprimento $\left(R^{2}=0,772\right)$, largura $\left(R^{2}=0,753\right)$, altura $\left(R^{2}=0,741\right)$ e peso vivo total $\left(R^{2}=0,611\right)$. A grande quantidade de fitoplâncton presente na área de estudos não pôde ser correlacionada com os demais fatores. Os resultados apontaram boas perspectivas para ostreicultura alagoana.

Palavras chave: 1 - ostra; 2 - crescimento; 3 - temperatura; 4 - salinidade; 5 - clorofila - a.

\section{ABSTRACT}

Oyster farming in Brazil began in 1970, but currently is concentrated mainly in the southern region, mainly based on the creation of the japanese oyster Crassostrea gigas (Thunberg, 1793). This study aimed to evaluate the potential of creating the native oyster Crassostrea rhizophorae (Guilding, 1828) and check the environmental variables that most influence their development. The "seeds" used at creation were collected in the natural environment and the experience lasted seven months, between february and august 2011. The culture system employed was type fixedsuspended in the intertidal zone of the San Miguel River estuary. The rainfall, salinity and temperature were the factors that most influenced the development of oysters. Salinity showed strong positive correlation with the monthly growth rate $\left(R^{2}=0.67\right)$ and temperature strong negative correlation with the parameters of length $\left(R^{2}=0.772\right)$, width $\left(R^{2}=0.753\right)$, height $\left(R^{2}=0.741\right)$ and weight total live $\left(R^{2}=0.611\right)$. The large amount of phytoplankton present in the study area could not be correlated with other factors. The results indicated good prospects for oyster farming in Alagoas.

Key-word: 1 - oyster; 2 - growth; 3 - temperature; 4 - salinity; 5 - chlorophyll - a.

\section{INTRODUÇÃO}

De acordo com os dados da FAO (2010), a produção mundial de pescado para o consumo humano em 2009 foi em torno de 119 milhões de toneladas, sendo 47\% dessa quantidade produzida pela aquicultura. $\mathrm{O}$ crescimento da aquicultura vem compensando o estancamento da

Contato: ${ }^{1}$ Departamento de Oceanografia da UFPE, Av. Arquitetura, s/n, Cidade Universitária. 
VILAR, T. C.; TENÓRIO, D. de O.; FEITOSA, F. A. do N. Criação experimental da ostra-do-mangue Crassostrea rhizophorae (Guilding, 1828) em barra de São Miguel, Alagoas.

pesca extrativista e segue seu crescimento anual médio com acúmulo de 8,3\% entre 1970 e 2008.

No Brasil, registros do Boletim Estatístico do Ministério da Pesca e Aquicultura, mostraram que em 2009 a Aquicultura brasileira correspondeu a cerca de 34\% da produção de pescado nacional. Entretanto, a atividade aquícola marinha responde por apenas $6,3 \%$ da produção no mesmo ano (MPA, 2009).

Em Alagoas, as ostras representam o terceiro molusco mais capturado no estado, ficando atrás apenas do sururu (Mytela falcata) e do maçunim (Tivela mactroides). A pesca de ostras em 2005 foi de 95,8 toneladas (IBAMA, 2007). Em contra partida, a ostreicultura alagoana produz cerca de 40mil dúzias ao ano (AECID, 2008).

Segundo o IBAMA (2005), 92\% das ostras cultivadas no Brasil foram da espécie Crassostrea gigas, produzidas principalmente no estado de Santa Catarina. Apenas três espécies do gênero Crassostrea são cultivadas no Brasil: a ostra japonesa Crassostrea gigas (Thunberg, 1793) e as ostras nativas Crassostrea rhizophorae (Guilding, 1828) e Crassostrea brasiliana (Lamarck, 1819).

A classificação das nativas é alvo de várias discussões entre os pesquisadores. Estas duas espécies vêm sendo consideradas sinonímias por diversos taxonomistas há anos (Abbott 1974; Rios, 1994). Recentemente, estudos genéticos afirmam que estas ostras são espécies diferentes (Ignácio et al., 2000; Lazoski, 2004). Entretanto, ainda há muitas controvérsias entre as diferenciações genéticas e as semelhanças conquiológicas. A diferenciação entre as espécies baseada apenas na concha é complicada, já que a estrutura apresenta plasticidade fenotípica e pode sofrer modificações provocadas por adaptações ao meio ambiente (Amaral, 2010). Rios (1994), baseado em caracteres morfológicos considerou que há apenas a espécie Crassostrea rhizophorae na costa brasileira e que todos os outros morfotipos são sinonímias.

Segundo Rios (1994) a distribuição de C. rhizophorae se dá do Caribe ao Uruguai e seus principais habitats são as raízes aéreas do Rhizophorae mangle e os substratos duros, como rochas no médio litoral, na região entremarés.

Mesmo com esforços científicos e fomento por parte do poder público em busca do desenvolvimento aquícola, a principal forma de consumo dos moluscos bivalves no Brasil ainda é através do extrativismo, que contribui para diminuição dos estoques naturais e causa comprometimento do ecossistema. A exploração comercial da ostra nativa é praticada por comunidades tradicionais de forma desordenada (Ferencz, 1991; Caldeira, 2004; Quinamo, 2006).

As espécies do gênero Crassostrea são consideradas eurihalinas e euritérmicas (Galtsoff, 1964; Quayle, 1988). Podem habitar diferentes ambientes, sobretudo estuários, onde há interação entre a água salgada e doce ocorrendo grandes variações de salinidade (Pritchard, 1967). Os estuários são propícios à ostreicultura, apresentando áreas protegidas, com grande aporte de matéria orgânica e alta produtividade primária.

A produção primária nos ecossistemas aquáticos está sempre na dependência dos efeitos sinergéticos dos fatores meteorológicos, físicos, químicos e biológicos, que limitam ou estimulam não só a atividade dos organismos planctônicos clorofilados, mas de todos os seres aquáticos (Passavante \& Feitosa, 2004).

No estuário, outros fatores ambientais, além da produtividade primária, podem influenciar direta ou indiretamente o desenvolvimento das ostras, como o tipo de substrato, profundidade, intensidade da corrente e da luz, ação dos ventos, variação da temperatura e a salinidade. Estas regiões podem sustentar, parcialmente ou por completo, o ciclo de vida dos organismos eurihalinos (Perillo, 1995).

Em estuários tropicais, geralmente a temperatura da água permanece em torno de $26^{\circ} \mathrm{C}$ $\pm 5^{\circ} \mathrm{C}$. As temperaturas mais altas se apresentam no período seco e as mais baixas no período chuvoso. De maneira geral, as ostras suportam grande variação de temperatura (Galtsoff, 1964).

A salinidade é um dos fatores mais estudados em criação de ostras, especialmente nos ambientes estuarinos. No Brasil, os locais de salinidades baixas (montantes) têm maior crescimento e as regiões com salinidades altas (foz) possuem maior número de larvas e as fixações larvais são contínuas (Fernandes, 1975; Nascimento et al., 1980; Poli, 2004). Wakamatsu (1973), concluiu que a ostra Crassostrea brasiliana era capaz de sobreviver a 
VILAR,T. C.; TENÓRIO, D. O.; FEITOSA, F. A. N. Criação experimental da ostra-do-mangue Crassostrea rhizophorae (Guilding, 1828) em Barra de São Miguel, Alagoas.

salinidades entre $8 \%$ e $34 \%$. A ostra-do-mague C. rhizophorae, por exemplo, é bem adaptada a sobreviver a exposições extremas de salinidade, entre $0 \%$ durante as marés baixas de períodos chuvosos e $40 \%$ em marés cheias de períodos secos, entretanto, a faixa mais comum de seu habitat é entre $7,2 \%$ e $28,8 \%$ o (Costa, 1975).

O estudo teve como objetivo avaliar o potencial de criação da ostra nativa Crassostrea rhizophorae e verificar as variáveis ambientais que mais influenciam o crescimento das ostras cultivadas na Barra de São Miguel, Alagoas.

\section{ÁREA DE ESTUDO}

A área de estudo está localizada no litoral sul do Estado de Alagoas, a cerca de $32 \mathrm{~km}$ da capital, Maceió. A Bacia Hidrográfica de São Miguel (Fig. 1), tem área total de $4.368,8 \mathrm{~km}^{2}$, com 16 municípios e cerca de 380.000 habitantes. Nesta bacia, há cinco principais rios, dentre eles, o Rio São Miguel é considerado o maior, com aproximadamente $80 \mathrm{~km}$ de extensão, segundo a Secretaria de Meio Ambiente e Recursos Hídricos de Alagoas(SEMARH-AL). Praticamente toda água oriunda da bacia percorre o rio São Miguel desde a meso-região do agreste alagoano até sua foz situada litoral. A criação das ostras fica na Lagoa do Roteiro ( $7 \mathrm{~km}$ da foz), no município de Barra de São Miguel.

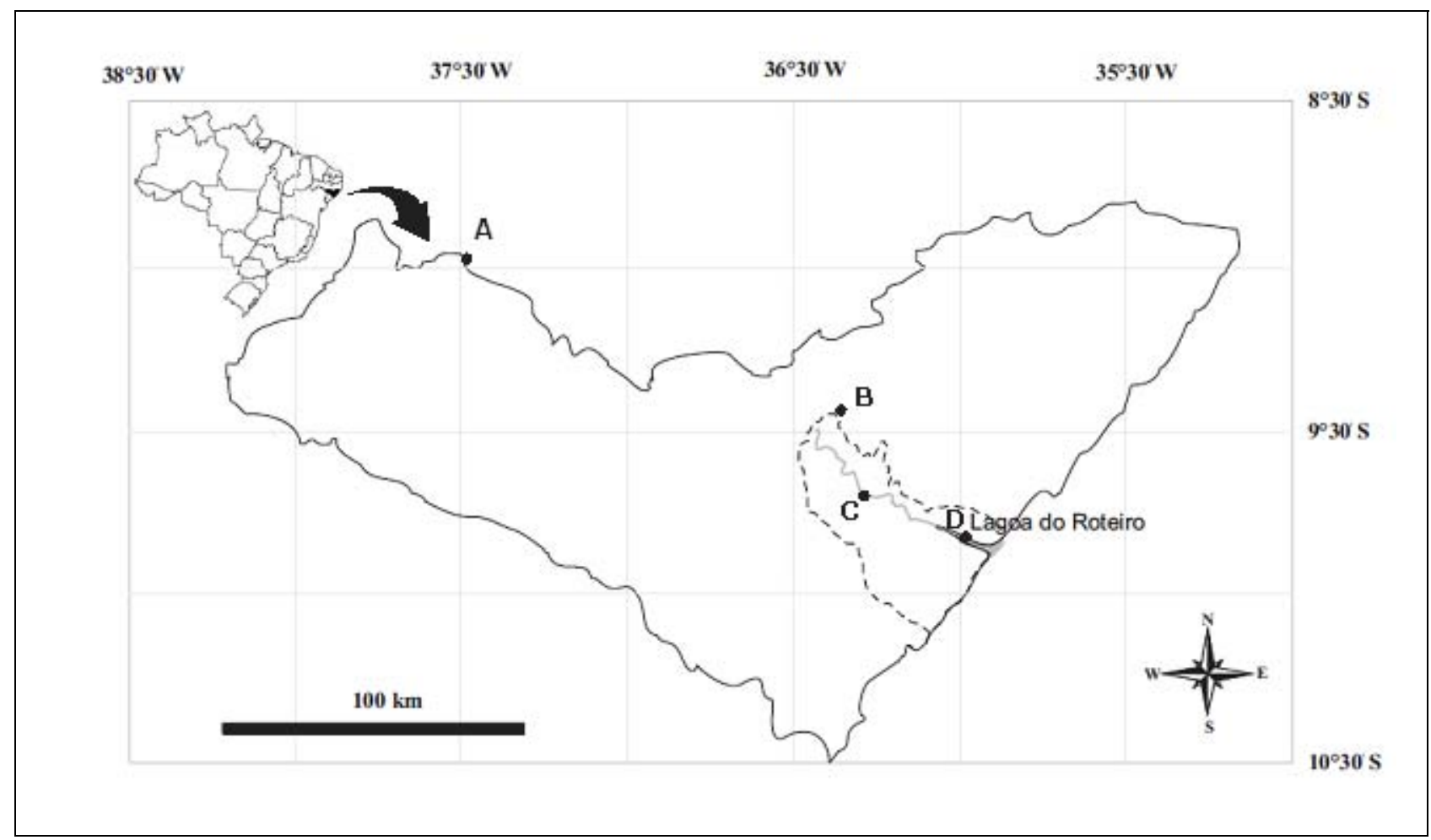

Figura 1 - A) Estado de Alagoas; B) Bacia de São Miguel; C) Rio São Miguel; D) Lagoa do Roteiro.

A criação de ostras está localizada a cerca de $7 \mathrm{~km}$ de distância da foz do rio São Miguel, no município de Barra de São Miguel, dentro da Reserva Ecológica Lagoa do Roteiro. A reserva abrange os municípios de Roteiro e Barra de São Miguel, conta com área total de 742 hectares, onde predomina o ecossistema manguezal (SEMARH-AL).

Às margens da Lagoa do Roteiro, há uma comunidade conhecida como Palatéia (Fig. 2), composta por cerca de 400 habitantes que vivem diretamente da produção de ostras. Estes ribeirinhos, adaptados a viver nas florestas de mangue, estão sempre buscando desenvolver tecnologias que venham gerar renda. A ostreicultura é a principal atividade econômica na comunidade e conta com a participação de 20 famílias.

Foi realizada uma criação experimental de ostras na área de estudo, acompanhada entre os meses de fevereiro e agosto de 2011 sob as coordenadas 950'14"S - 3557'28"W. 
VILAR, T. C.; TENÓRIO, D. de O.; FEITOSA, F. A. do N. Criação experimental da ostra-do-mangue Crassostrea rhizophorae (Guilding, 1828) em barra de São Miguel, Alagoas.

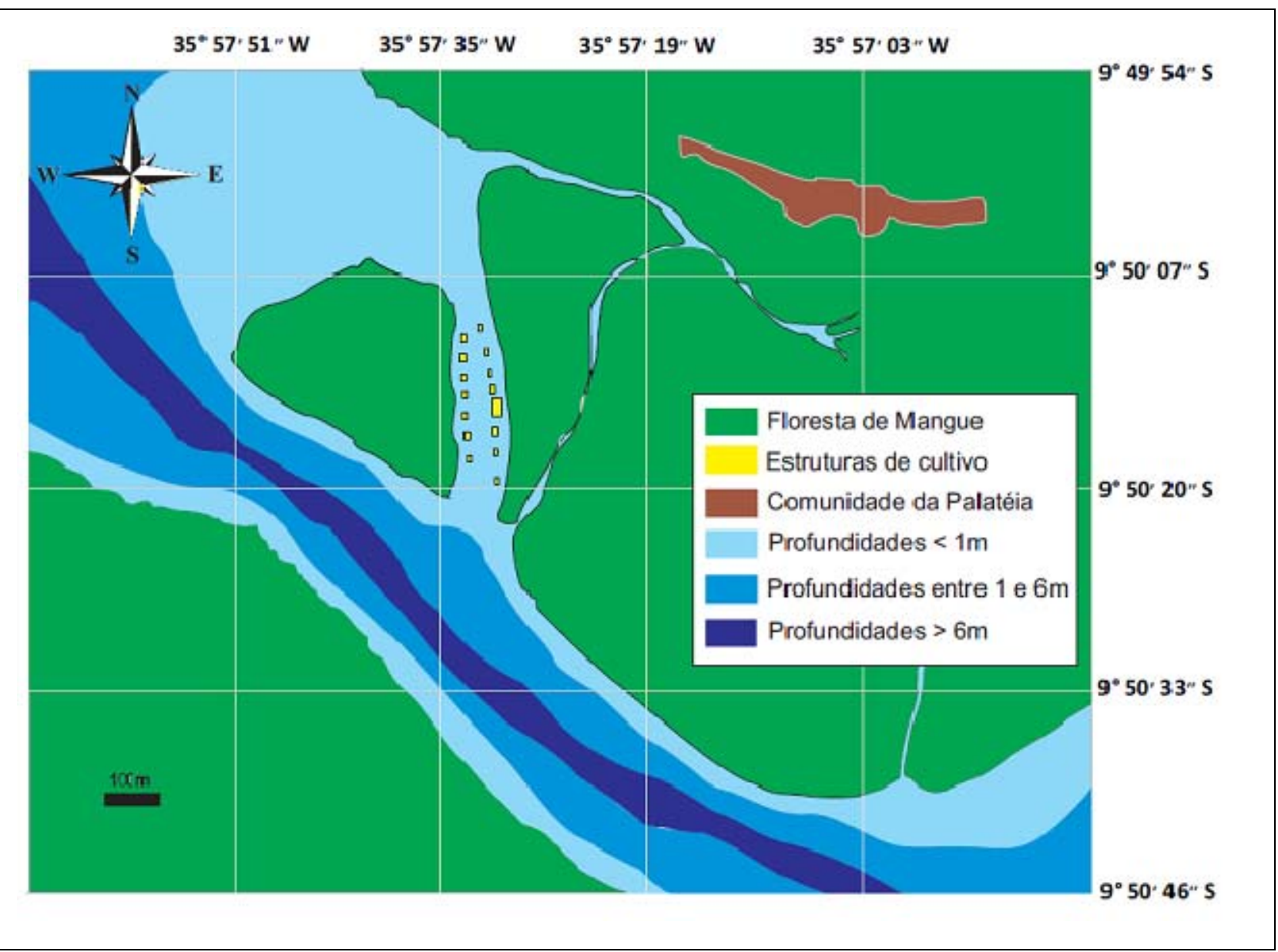

Figura 2 - Zoneamento da área de estudo.

\section{MATERIAL E MÉTODOS}

\section{Variáveis Ambientais}

As variáveis abióticas de temperatura, salinidade, $\mathrm{pH}$ e transparência foram aferidas mensalmente durante os períodos de preamar e baixa-mar, ambos na maré de sizígia, entre fevereiro e agosto de 2011. Para tais medidas foram utilizados um termômetro de mercúrio analógico, um refratômetro, um kit pH por colorimetria e um disco de Secchi, respectivamente.

Os índices de pluviometria foram procedentes da Secretaria do Estado de Meio Ambiente e Recursos Hídricos do Estado de Alagoas (SEMARH-AL). Os dados utilizados neste trabalho foram do posto Usina Roçadinho - Foz do Patrício (Roteiro), situado cerca de $1 \mathrm{~km}$ de distância do ambiente de criação, localizado à montante.

Para a análise de clorofila-a, foram coletadas amostras mensais de água durante os períodos de baixa-mar e preamar das marés de sizígia. O material coletado foi mantido refrigerado e protegido de luz até que fosse transportado para o laboratório de Fitoplâncton Marinho do Departamento de Oceanografia da Universidade Federal de Pernambuco (DOCEANUFPE). A filtragem foi feita com filtro de fibra de $45 \mu \mathrm{m}$ e acondicionado seco em papel alumínio em ambiente refrigerado. Por fim, o filtro contendo o plâncton da amostra foi diluído em acetona 90\% e aferido no espectrofotômetro de acordo com Strickland e Parsons (1972).

\section{Sistema de criação e captação de sementes}

Para implantação do experimento, foram coletadas sementes e juvenis de Crassostrea rhizophorae, com cerca de $4 \mathrm{~cm}$ de comprimento. As ostras puderam ser encontradas aderidas aos mais diversos tipos de substrato duro, junto a criação, em ambiente natural. Cerca de 1500 ostras foram raspadas, limpas e separadas para o experimento.

O sistema de criação utilizado no experimento foi fixo-suspenso do tipo "mesa" (Fig.3). A estrutura foi confeccionada com tubos PVC de $40 \mathrm{~mm}$, com dimensões de $200 \times 80 \times 120 \mathrm{~cm}$ (comprimento, largura, altura). Sobre a mesa, foi colocada uma trama plástica de jardim com cerca de $1 \mathrm{~cm}$ de diâmetro de malha, para que houvesse boa sustentação e proteção das ostras 
VILAR,T. C.; TENÓRIO, D. O.; FEITOSA, F. A. N. Criação experimental da ostra-do-mangue Crassostrea rhizophorae (Guilding, 1828) em Barra de São Miguel, Alagoas.

contra as ações dos predadores e das variações da maré. A altura da mesa após a instalação foi de cerca de $80 \mathrm{~cm}$, pois $40 \mathrm{~cm}$ ficaram soterrados para equilíbrio da estrutura.

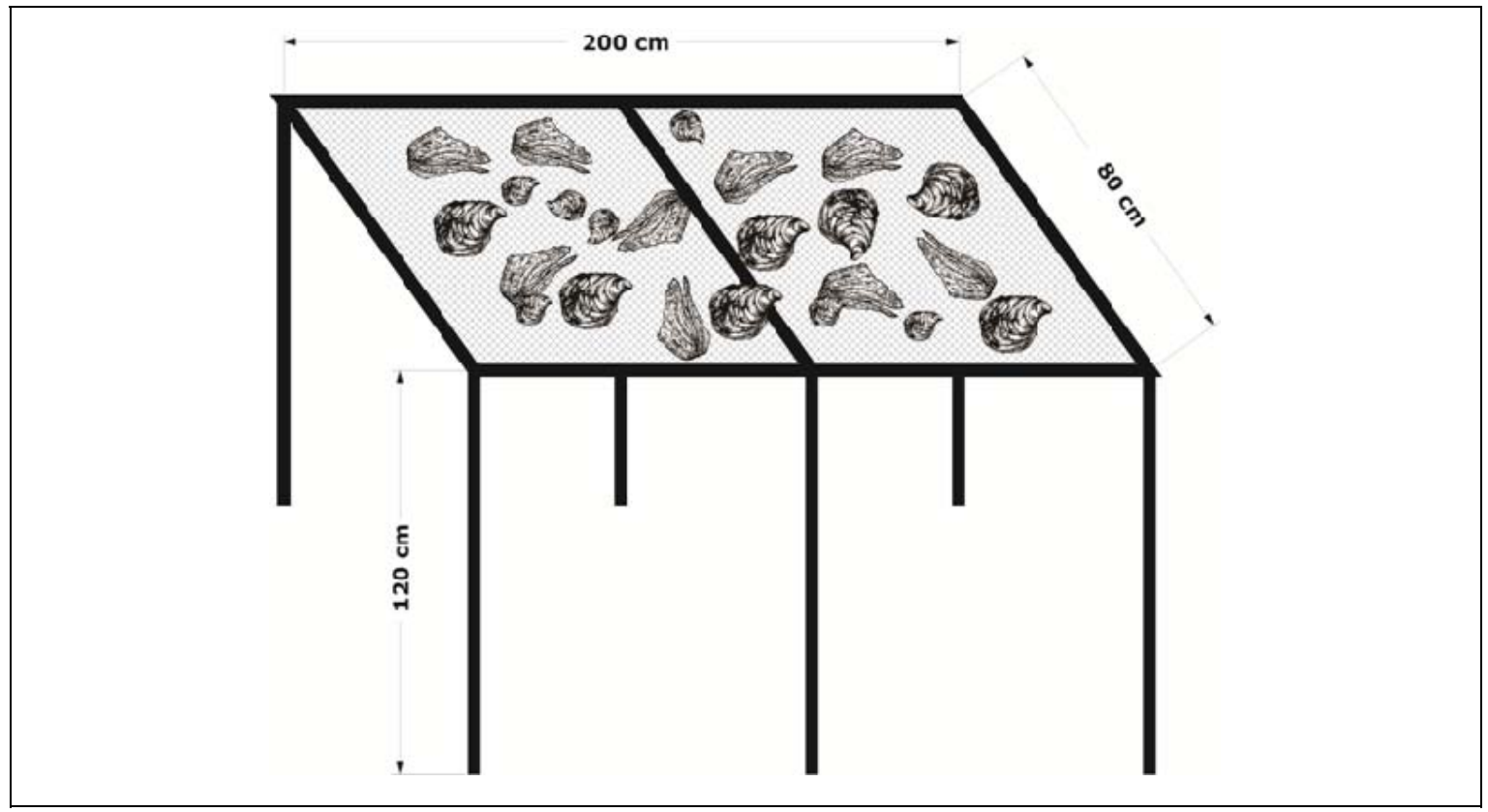

Figura 3 - ilustração da estrutura ("mesa").

\section{Mensurações biológicas}

A biometria foi realizada mensalmente com cerca de 30 animais. As medidas de altura, comprimento e largura foram aferidas com paquímetro simples. A orientação das medidas foram de acordo com o Manual de Maricultura do Ministério de Pesca e Aquicultura, conforme ilustrado na figura 4.

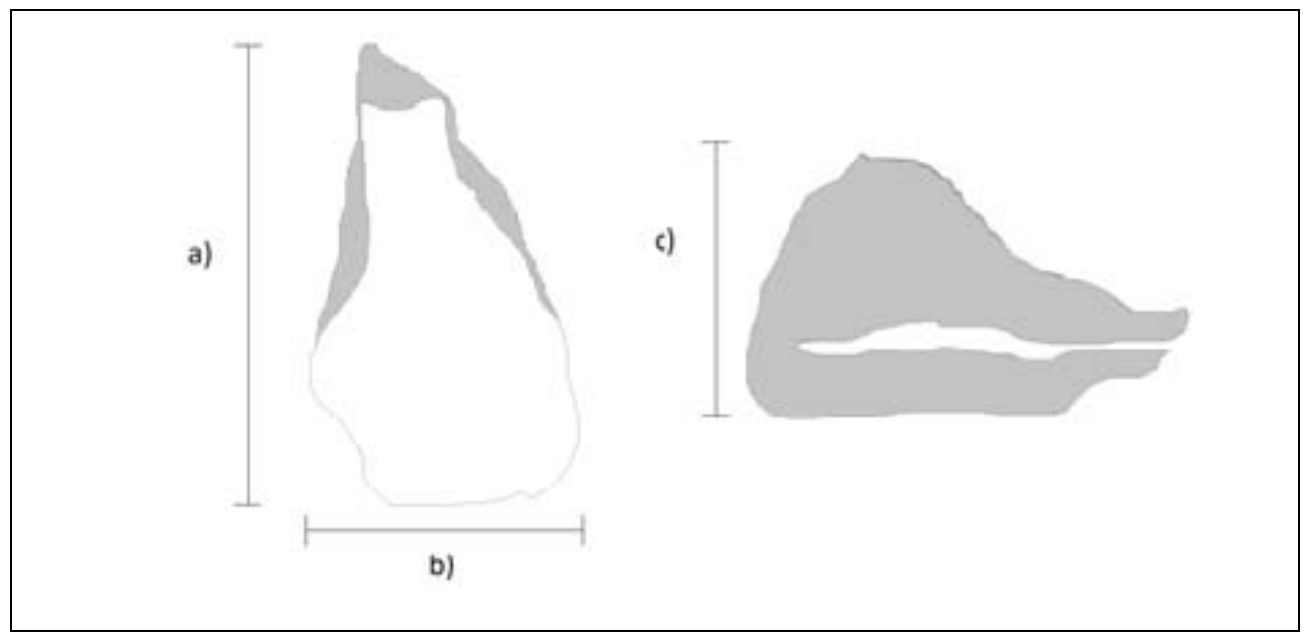

Figura 4 - orientação biométrica das ostras; a) comprimento, b) largura e c) altura.

Após a biometria, foram aferidos o Peso Vivo Total (PVT) das ostras. No decorrer dos meses foram calculadas as Taxas de Crescimento Mensal (TCM) tomando como base o parâmetro de comprimento. Então: Taxa de Crescimento Mensal $(\mathrm{TCM})=$ comprimento do mês atual comprimento do mês anterior.

\section{Fator de Condição (FC)}

Neste trabalho foram realizadas medidas referentes ao Percentual de Carne Cozida das ostras com intuito de identificar se a engorda das ostras pode estar diretamente associada às flutuações dos níveis de clorofila-a aferidas no ambiente.

O método de avaliação do Percentual de Carne Cozida (PerCC) consistiu em cozinhar o lote de ostras $(n=30)$ em água fervente por 5 minutos, escorrer a carne cozida por 5 minutos e pesa- 
VILAR, T. C.; TENÓRIO, D. de O.; FEITOSA, F. A. do N. Criação experimental da ostra-do-mangue Crassostrea rhizophorae (Guilding, 1828) em barra de São Miguel, Alagoas.

las. Então, para obter o Percentual de Carne Cozida, calculou-se: peso da carne cozida x 100 / peso vivo total $=$ PerCC.

\section{Análises Estatísticas}

As análises estatísticas foram realizadas com ajuda de dois programas de computador, o Microsoft Excel 2010 e o XLSTAT.

Os gráficos de temperatura, salinidade, pluviometria, clorofila-a e parâmetros de crescimento foram confeccionados com ajuda do Microsoft Excel 2010, determinando o namostral $(n=30)$, calculando-se cada respectivo desvio padrão e adotando-se o alfa de 0,05 para determinação do intervalo de confiança.

A análise dos componentes principais (ACP) foi realizada com o programa XLSTAT. As variáveis utilizadas foram pluviometria, transparência, temperatura, salinidade, $\mathrm{pH}$, clorofila-a (Cl-a), comprimento, largura, altura, taxa de crescimento mensal (TCM), peso vivo total (PVT) e o fator de condição (FC).

As análises de regressão linear simples foram realizadas com o XLSTAT onde foi possível avaliar as correlações entre as variáveis estudadas (Pearsons).

\section{RESULTADOS}

\section{Análise dos Componentes Principais}

Para o tratamento dos dados, foi realizada uma Análise dos Componentes Principais (ACP) com as médias de todas as variáveis ambientais e biometrias (Fig. 5).

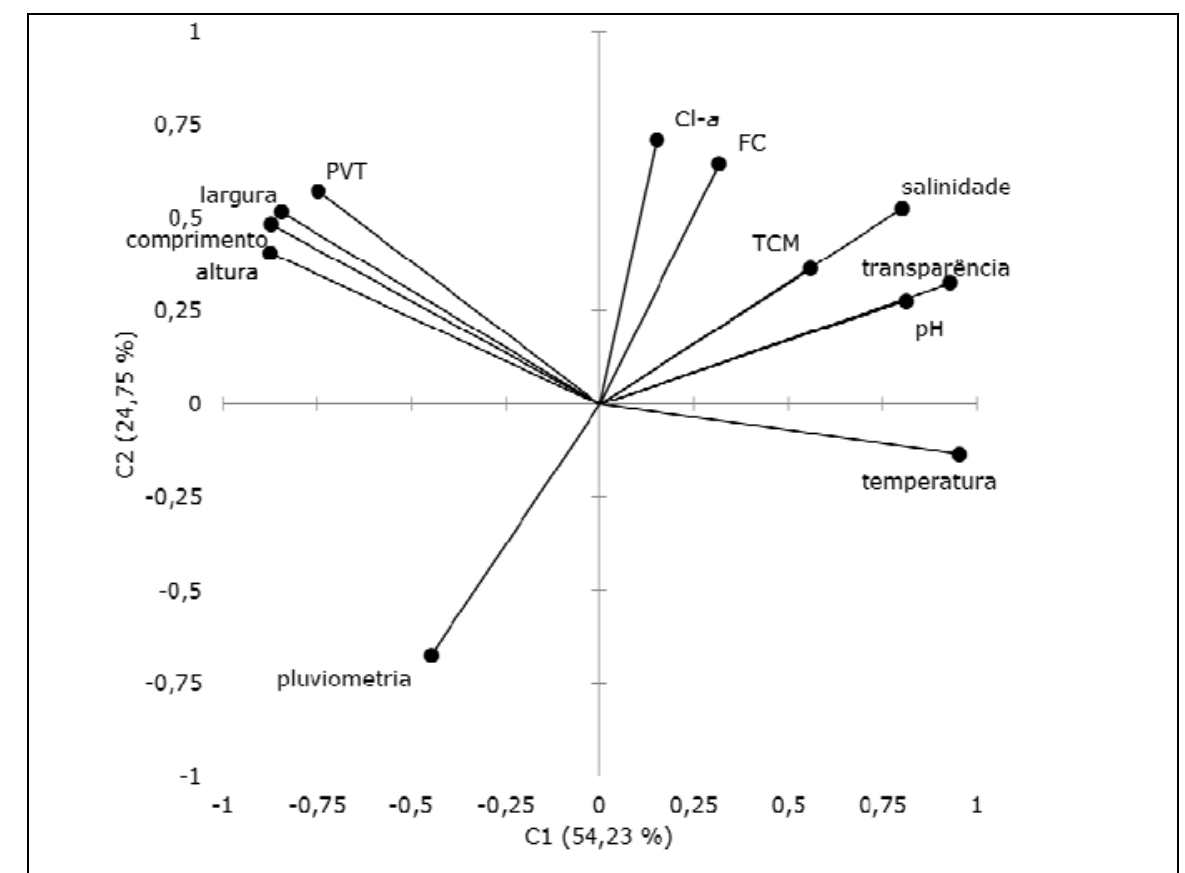

Figura 5 - Análise dos Componentes Principais (ACP). Peso Vivo Total (PVT); Fator de Condição (FC); Taxa de Crescimento Mensal (TCM)

As duas primeiras componentes ( $\mathrm{C} 1$ e $\mathrm{C} 2$ ) explicaram cerca de $78 \%$ da variância total. A primeira componente (C1) explicou $54,23 \%$ da variância total e a segunda componente (C2) explicou $24,75 \%$ da variância total.

Duas principais tendências podem ser visualizadas na figura 5. A primeira, referente à componente um (C1) evidencia a forte correlação negativa (inversamente proporcional) entre a temperatura e os parâmetros de comprimento, largura, altura e peso vivo total. A componente dois (C2) apresenta a forte correlação negativa entre a pluviometria e os parâmetros de salinidade, taxa de crescimento mensal (TCM), transparência e pH.

\section{Variáveis Ambientais}

Tabela 1 - Acumulado pluviométrico \& médias das variáveis ambientais coletadas na preamar e baixa-mar de cada mês.

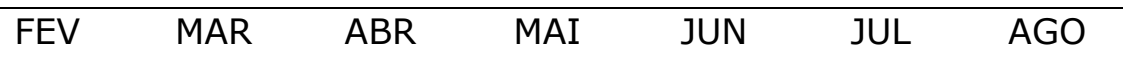


VILAR,T. C.; TENÓRIO, D. O.; FEITOSA, F. A. N. Criação experimental da ostra-do-mangue Crassostrea rhizophorae (Guilding, 1828) em Barra de São Miguel, Alagoas.

\begin{tabular}{lccccccc} 
Pluviometria & 135 & 100 & 560 & 339 & 171 & 358 & 131 \\
$\mathrm{pH}$ & 7,6 & 7,4 & 7,2 & 7,2 & 7,2 & 7,2 & 7,4 \\
Transparência & 25 & 25 & 20 & 15 & 20 & 15 & 20 \\
Temperatura & 30,5 & 29 & 28,5 & 25,5 & 26 & 25 & 26 \\
Salinidade & 19,5 & 26 & 14 & 8 & 16 & 7,5 & 17,5 \\
Cl-a & $\mathrm{NC}$ & 13,575 & 6,22 & 9,305 & 6,39 & 8,455 & 18,405 \\
\hline
\end{tabular}

\section{Precipitação pluviométrica}

Os níveis de pluviometria se mantiveram baixos durante os meses de fevereiro e março, com grande elevação na quantidade de chuva a partir de abril (Fig. 6). O regime de chuvas na área de estudos foi atípico no ano de 2011, com grande intensidade de chuva no mês de abril (período seco) e com leves pancadas de chuva no mês de junho (período chuvoso). Entretanto, a pluviometria manteve forte correlação negativa do com a salinidade $\left(R^{2}=0,428\right)$. Tornando 0 ambiente de cultivo menos salino nos meses mais chuvoso, chegando a atingir o nível extremo de $0 \%$ na baixa-mar de julho.

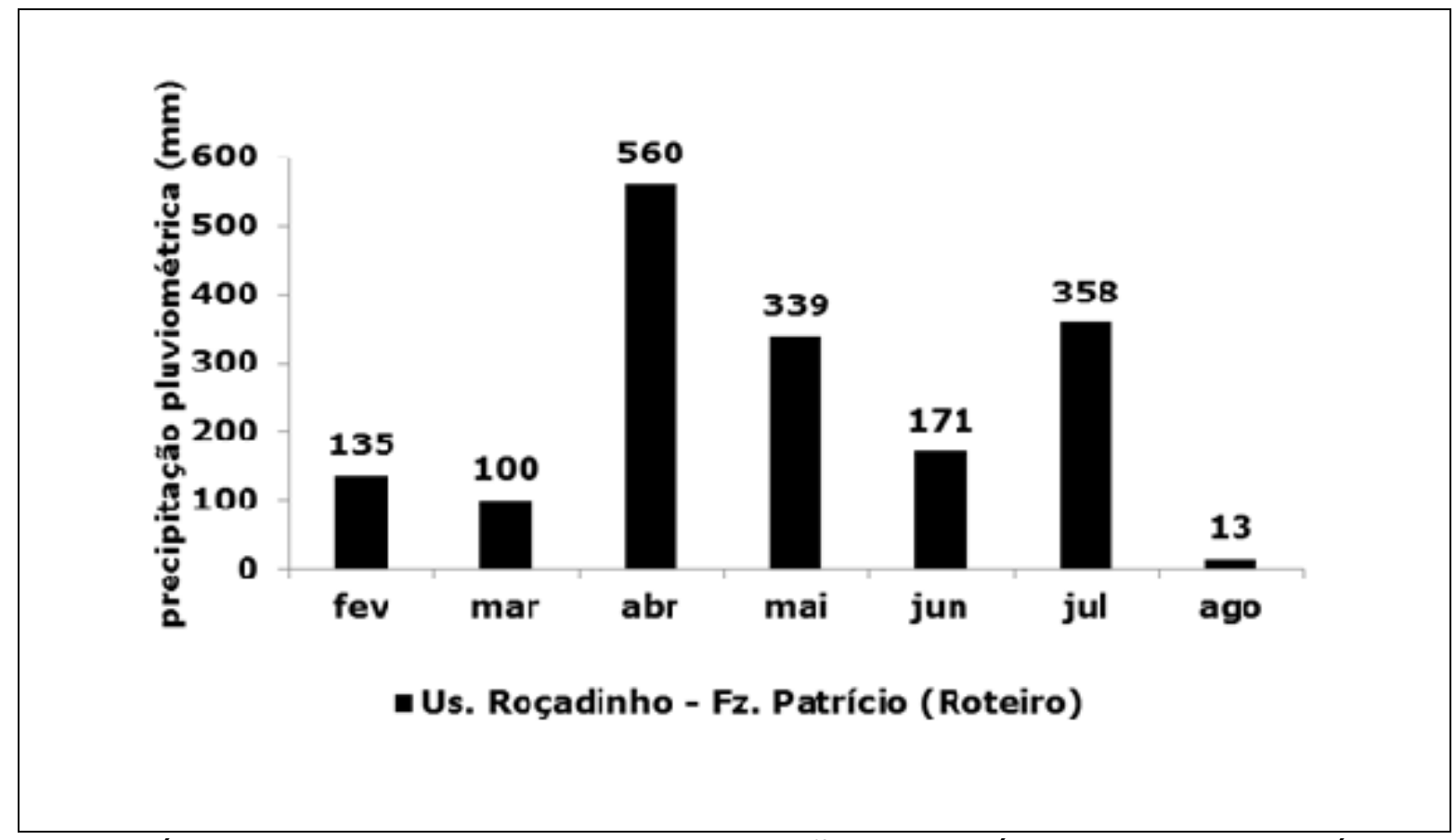

Figura 6 - Níveis acumulados mensais de precipitação pluviométrica na Foz do Patrício(Roteiro) em 2011 (fonte: SEMARH).

\section{pH e Transparência}

Os parâmetros de $\mathrm{pH}$ e transparência foram os que obtiveram menos variações no decorrer do experimento. $\mathrm{O}$ pH médio oscilando em torno de 7,4 e a transparência média variando entre 15 e $25 \mathrm{~cm}$ de visibilidade.

\section{Salinidade}

Os níveis de salinidade apresentaram níveis inferiores durante a baixa-mar se comparados com a preamar. Este fato ocorreu durante todo período de experimento, tanto nos meses mais secos quanto nos meses mais chuvosos. As médias mensais oscilaram entre 8 e $26 \%$. Março apresentou salinidades mais elevadas enquanto maio e julho apresentaram os menores índices de salinidade (Fig. 7A). A variação diurna da salinidade aferida em abril apresentou oscilação de $10 \%$ (Fig. 7B). Na análise de regressão linear a salinidade apresentou-se intimamente ligada a taxa de crescimento mensal $\left(R^{2}=0,675\right)$. 
VILAR, T. C.; TENÓRIO, D. de O.; FEITOSA, F. A. do N. Criação experimental da ostra-do-mangue Crassostrea rhizophorae (Guilding, 1828) em barra de São Miguel, Alagoas.

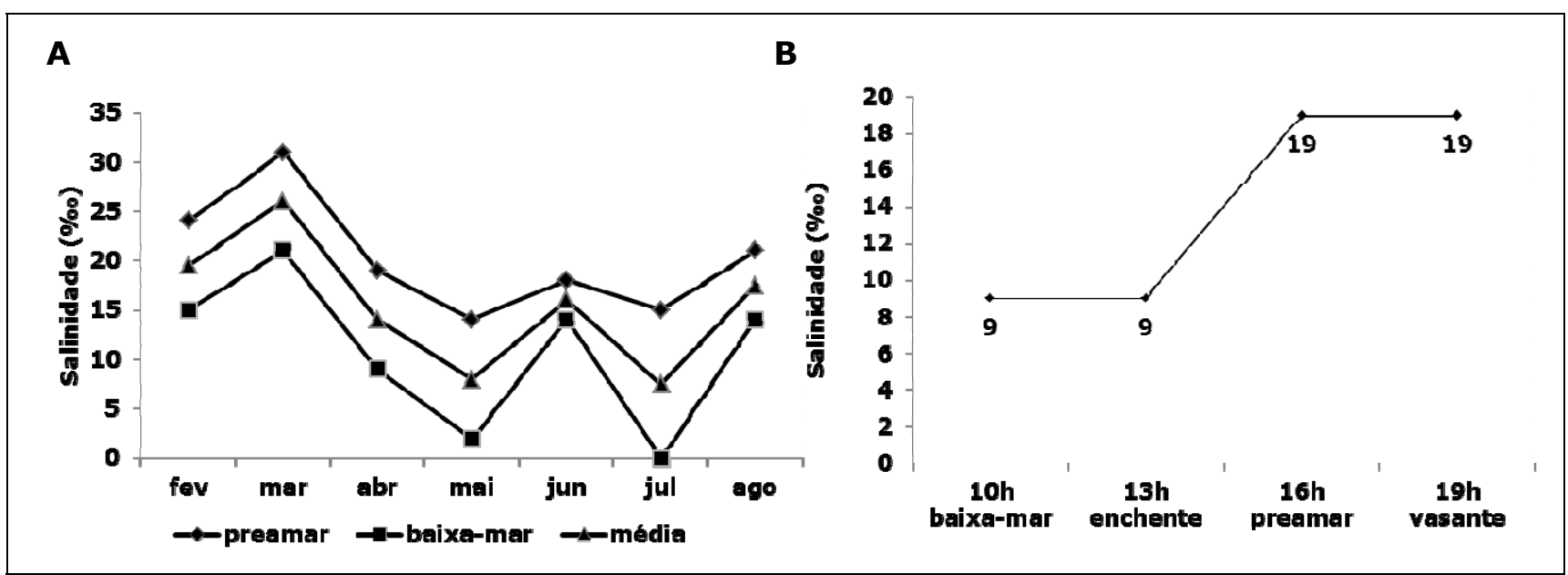

Figura 7 - A - salinidade entre fevereiro e agosto de 2011; B - variação diurna da salinidade em 19/04/2011.

\section{Temperatura da água}

A temperatura da água no ambiente de cultivo mostrou variação bem comum entre a baixamar e a preamar, sempre com temperaturas mais altas no período de baixa-mar e mais baixas na preamar. Quanto à média das temperaturas aferidas (Fig. $8 \mathrm{~A}$ ), pode-se observar que os meses mais quentes foram fevereiro, março e abril, enquanto que, maio, junho, julho e agosto apresentaram temperaturas amenas, inferiores a $28^{\circ} \mathrm{C}$. A variação diurna aferida em abril apresentou amplitude térmica de $4^{\circ} \mathrm{C}$ (Fig. 8B).

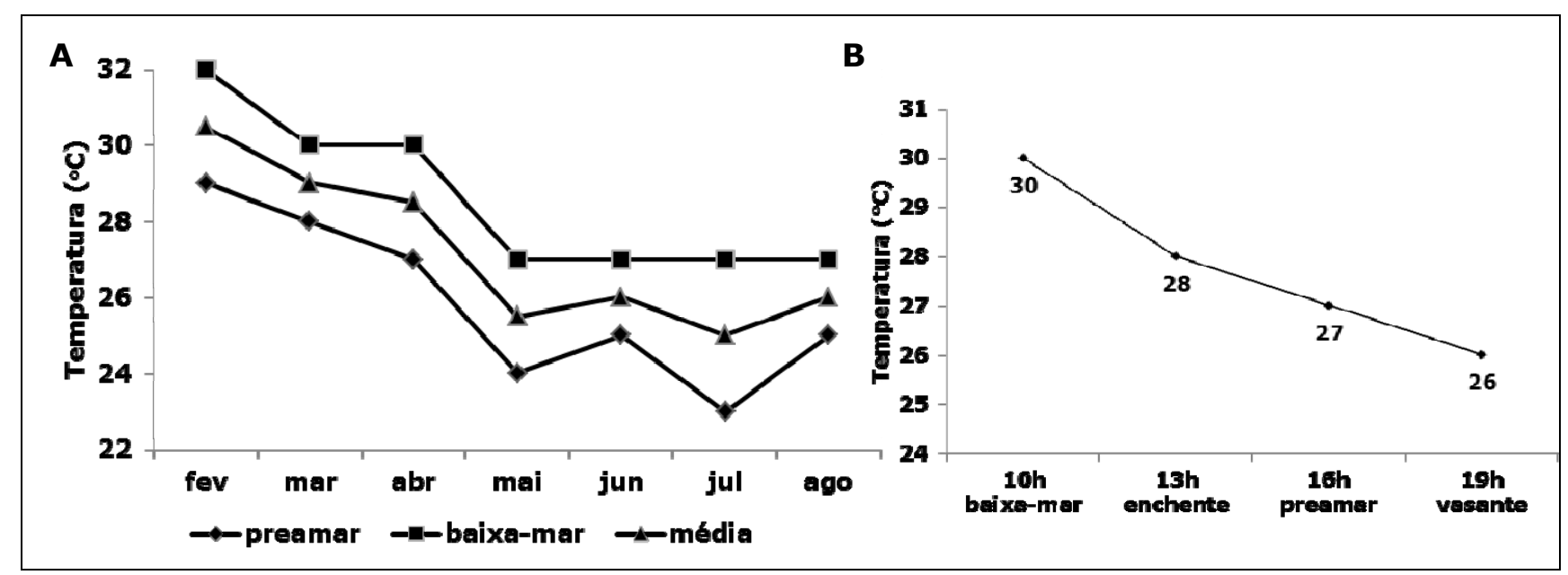

Figura 8 - A- temperatura da água entre fevereiro e agosto de 2011 . B - variação diurna da Clorofila-a temperatura em 19/04/2011.

As medidas de clorofila-a apresentaram grandes variações e não puderam ser correlacionadas com o fator de condição aferido $\left(R^{2}=0,055\right)$. As maiores oscilações ocorreram principalmente nos meses de maio, julho e agosto (Fig. 9A). Quanto a variação diurna da clorofila-a aferida em abril de 2011, os níveis oscilaram entre 10,16 e 2,28 mg. I $^{-1}$ (Fig. 9B). 
VILAR,T. C.; TENÓRIO, D. O.; FEITOSA, F. A. N. Criação experimental da ostra-do-mangue Crassostrea rhizophorae (Guilding, 1828) em Barra de São Miguel, Alagoas.
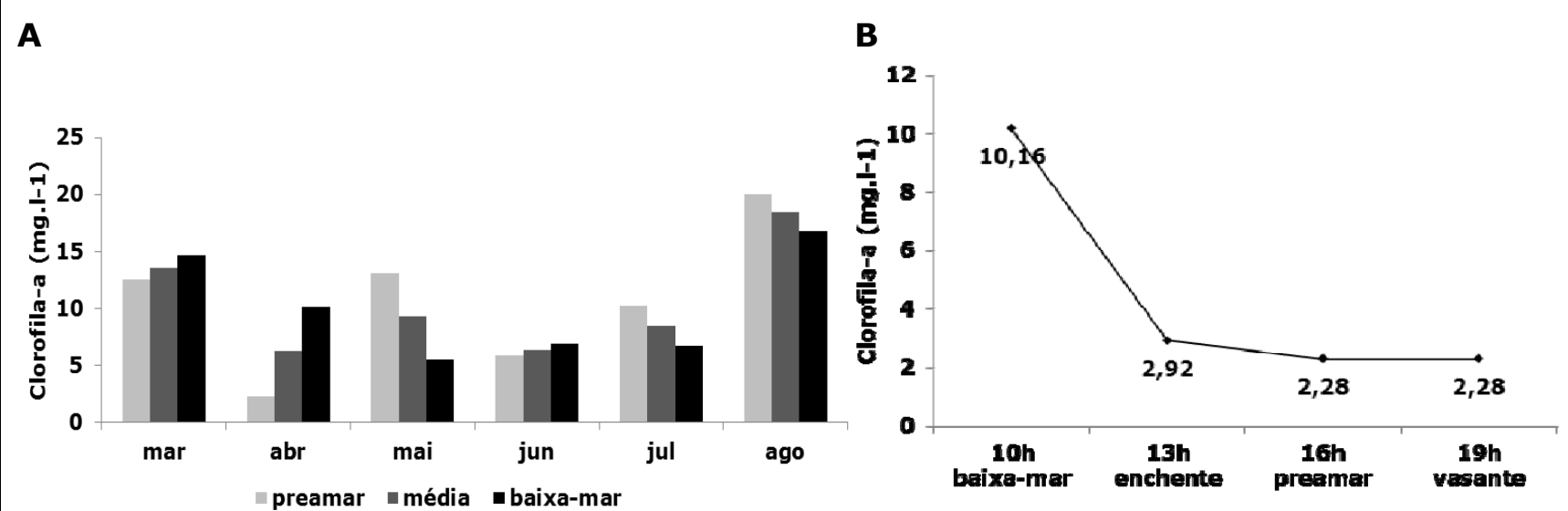

Figura 9 - A- clorofila-a entre março e agosto de 2011. B - Variação diurna da clorofila-a aferida em 19/04/2011.

\section{Crescimento}

Os parâmetros relativos ao crescimento (Fig. 10) apresentaram melhor desenvolvimento no meses de menor temperatura entre junho e agosto. A temperatura apresentou forte correlação negativa com os parâmetros de comprimento $\left(R^{2}=0,772\right)$, largura $\left(R^{2}=0,753\right)$, altura $\left(R^{2}=0,741\right)$ e peso vivo total $\left(R^{2}=0,611\right)$. Porém o parâmetro de comprimento melhor se correlacionou com o peso vivo total das ostras $\left(R^{2}=0,888\right)$.

A

C
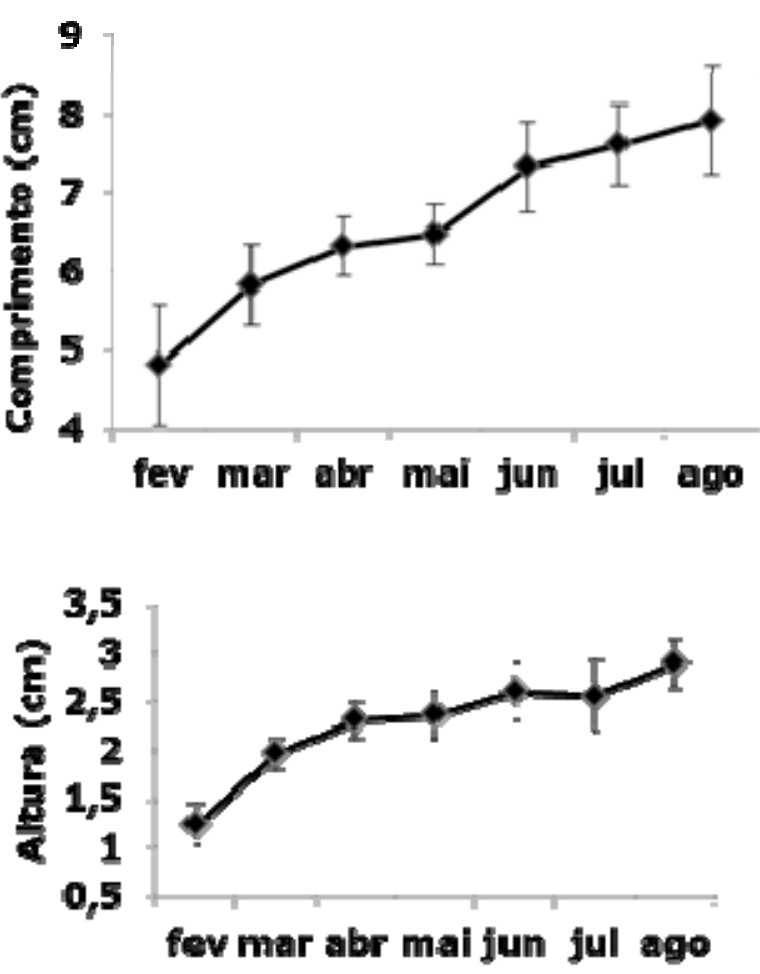

B

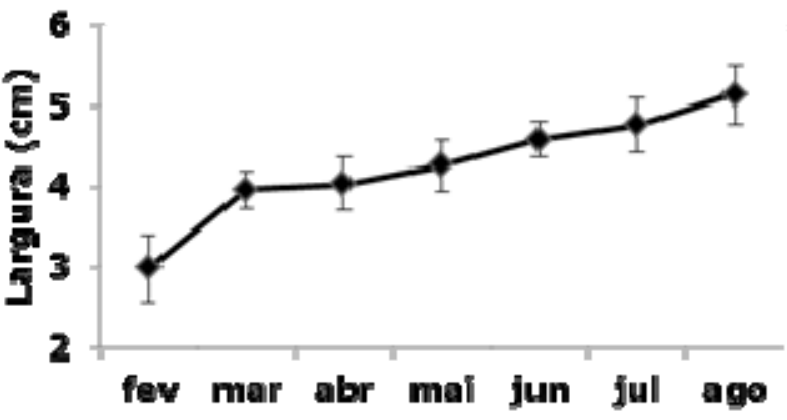

D

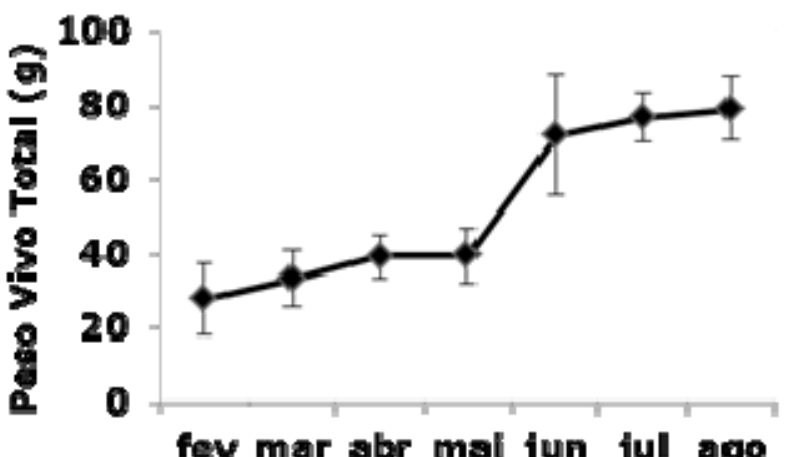

Figura 10 - Crescimento das ostras (alfa 0,05): A - comprimento; B - altura; C - largura; D peso vivo total.

\section{Taxa de Cescimento Mensal (TCM)}

O crescimento mensal das ostras mostrou forte correlação positiva com a salinidade, $R^{2}=$ 0,675 (Fig. 11). 
VILAR, T. C.; TENÓRIO, D. de O.; FEITOSA, F. A. do N. Criação experimental da ostra-do-mangue Crassostrea rhizophorae (Guilding, 1828) em barra de São Miguel, Alagoas.

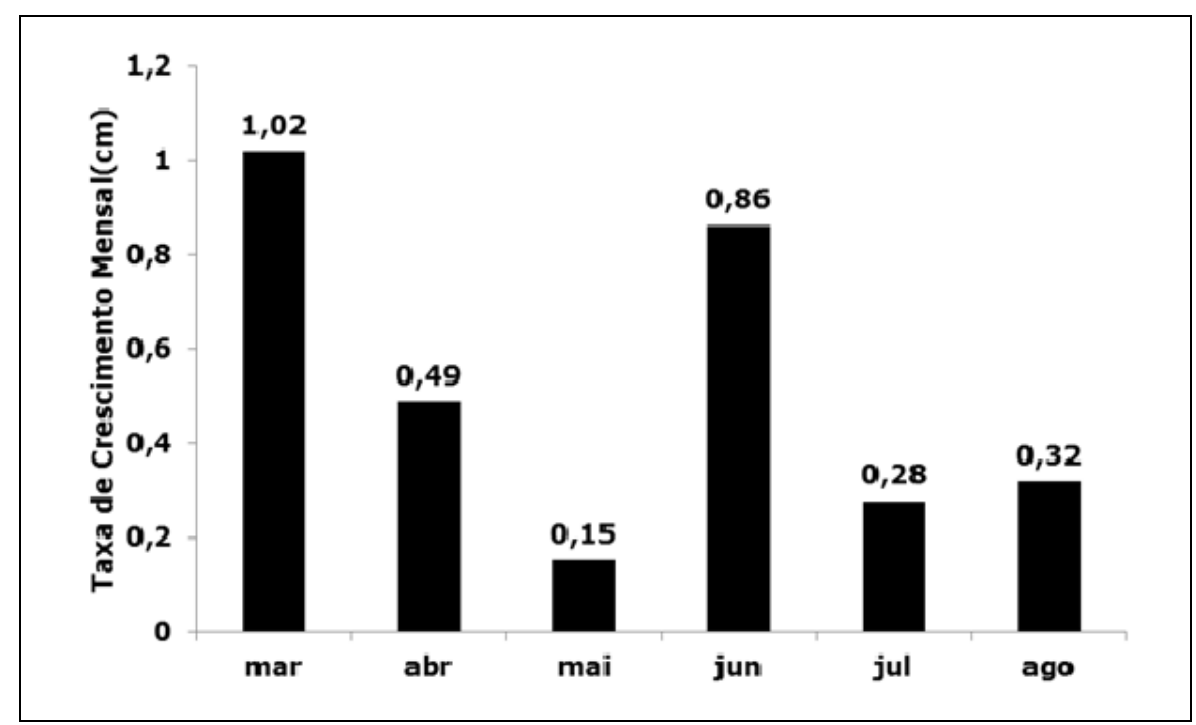

Figura 11 - Taxa de Crescimento Mensal (TCM)

\section{Fator de Condição (FC)}

O fator de condição adotado (Fig. 12) não pôde ser correlacionado com a clorofila-a aferida neste trabalho $\left(R^{2}=0,055\right)$. O pior índice de rendimento de carne foi aferido no mês de maio, logo após o alto índice de precipitação pluviométrica registrado no mês de abril.

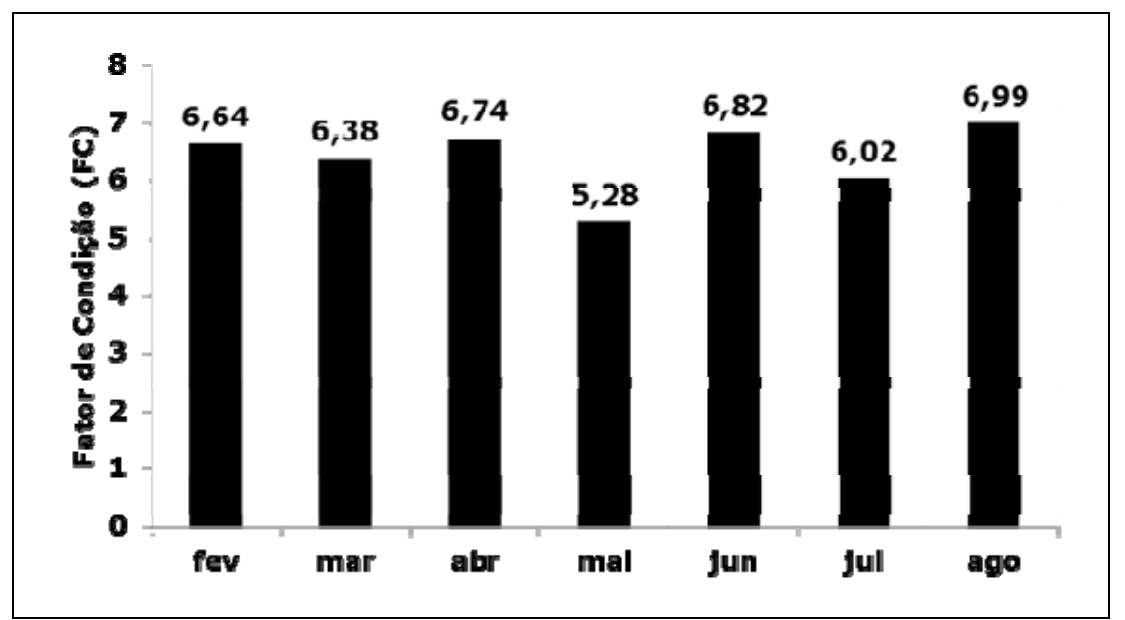

Figura 12 - Fator de condição (Percentual de Carne Cozida).

\section{DISCUSSÃO}

Neste experimento, o monitoramento das variáveis ambientais causou bom entendimento dos principais fatores que influenciam o crescimento das ostras Crassostrea rhizophorae criadas na Lagoa do Roteiro. A partir da análise dos componentes principais, foi possível avaliar a importância de dois principais fatores, temperatura e salinidade, capazes de influenciar o crescimento destas ostras.

A princípio, o regime pluviométrico da área de estudo no ano de 2011 apresentou grande variação se comparado à normal climatológica do litoral alagoano (SEMARH-AL). Porém, as variações nos índices pluviométricos estiveram conectadas aos níveis de salinidade. Quanto mais alto os níveis de acúmulo de chuva, menores os níveis de salinidade aferidos na área de estudo.

A localização da criação no estuário ( $7 \mathrm{~km}$ da foz) associada ao regime de chuvas na área, provavelmente, foi de grande contribuição para a elevação do grau de turbidez na área de estudos. Trata-se de uma zona de intensa mistura de massas de água doce e salgada, onde a salinidade chega a atingir altos níveis de flutuação entre a preamar e a baixa mar. Talvez a ampla variação da salinidade (31\%o), somada as variações na amplitude da maré (cerca de $2 \mathrm{~m}$ ) e a dinâmica hidrológica local sejam favoráveis ao bom desenvolvimento desses moluscos.

Os valores da salinidade reforçaram a ideia que o cultivo teve grande influência do rio e da chuva, por ter atingido níveis extremamente baixos de salinidade na área. Tal estresse ambiental pode ter influenciado o desenvolvimento das ostras. Costa (1975) considera C. rhizophorae uma 
VILAR,T. C.; TENÓRIO, D. O.; FEITOSA, F. A. N. Criação experimental da ostra-do-mangue Crassostrea rhizophorae (Guilding, 1828) em Barra de São Miguel, Alagoas.

espécie eurihalina, visto que a faixa mais comum de salinidade em seu habitat natural é entre $7,2 \%$ a $28,8 \%$ o.

As medidas de transparência aferidas pelo disco de secchi não apresentaram grandes diferenças na área de cultivo. A limitação da penetração da luz causada pela turbidez tem sido frequentemente assinalada como um fator controlador da produção primária em estuários (Randall \& Day, 1987; Lehman, 1992). Com o aumento dos índices pluviométricos no estuário, a presença de alta turbidez em estuários influencia muito nos processos biológicos na coluna d'água (Irigoien \& Castel,1997). Entretanto, o fato da transparência se manter constante numa zona de intensa mistura pode favorecer a produtividade primária dependendo das condições de luminosidade.

Certamente, com o aumento dos índices pluviométricos, outros fatores abióticos como o pH e a salinidade, puderam ser influenciados entre fevereiro e agosto de 2011 . Os Valores de pH no presente estudo teve poucas variações. Nesse caso, $\mathrm{o}$ pH não afetou significativamente outros parâmetros aferidos, pois assinalou variações típicas de ambiente estuarino, variando entre o pH neutro (7) e pH com tendências mais básicas em torno de 7,6 devido ao aporte de água salgada recebida durante a preamar.

A temperatura é uma variável física de grande importância na produtividade biológica da água, sendo considerada um dos fatores ecológicos decisivos dentro do sistema estuarino (Sipaúba-Tavares 1998). No Nordeste a temperatura dos estuários é sempre elevada e as pequenas variações que ocorrem durante o ciclo sazonal, dependem do grau de insolação e de outras condições meteorológicas (Honorato da Silva et al. 2004). Nesse sentido, a variação da temperatura ao longo do ano aconteceu conforme o padrão na área de estudo. As maiores temperaturas no períodos seco, enquanto as menores temperaturas foram aferidas no período chuvoso, pincipalmente nos meses de junho e julho, quando ocorre grande quantidade de nuvens diminui o grau de insolação. A diminuição dos níveis de temperatura incrementaram ganhos no crescimento, largura, altura e peso vivo total. Tal fato pode ter ocorrido devido à desaceleração do metabolismo das ostras, pois em temperaturas mais brandas as ostras gastam menos energia.

Os valores de clorofila-a aferidos no ambiente de cultivo podem ser considerados satisfatórios, suficiente para alimentar estes moluscos filtradores. A alta produtividade primária disponível para o cultivo segue de acordo com a recomendação para escolha da área de cultivo. 0 nível mínimo da produção primária diária desejada é de $4 \mathrm{mg} \cdot \mathrm{m}^{-3}$ de clorofila-a para Crassostrea gigas (Poli, 2004). Segundo estudos realizados por Lopes (2010), a clorofila-a apresenta correlação positiva com a taxa de crescimento diário. Entretanto os índices de clorofila-a estudados na Lagoa do Roteiro não puderam ser correlacionados nem com o crescimento, nem com o status nutricional das ostras, aferido através do fator de condição adotado.

Talvez o principal alimento das $C$. rhizophorae neste cultivo tenha sido algum tipo de material orgânico particulado diferente dos vegetais clorofilados, ou até mesmo, diversos grupos de bacterioplânctons presentes na coluna d'água.

O experimento realizado na Lagoa do Roteiro (Barra de São Miguel) atingiu boa média na taxa de crescimento mensal $(0,51 \mathrm{~cm})$. É possível afirmar que a linhagem das ostras utilizadas neste experimento tem grande potencial para produção aquícola. Outro cultivo realizado com a espécie considerada sinônima (Crassostrea brasiliana) no litoral Sudeste atingiu taxas médias de crescimento mensal de $0,27 \mathrm{~cm}$ (Pereira, 2001). É possível que as condições ambientais encontradas no Nordeste do Brasil possam favorecer o crescimento das ostras no litoral alagoano.

Este estudo mostrou que, em sete meses, é possível criar ostras nativas de forma sustentável, gerando emprego e renda para as comunidades. Ademais, é necessário que haja fomento dos órgãos públicos para desenvolvimento da aquicultura familiar tanto em Alagoas, quanto em todo o Brasil.

\section{CONCLUSÕES}

1. A temperatura e a salinidade foram os fatores que mais influenciaram o desenvolvimento das ostras cultivadas na Lagoa do Roteiro em 2011.

2. A alta produtividade primária disponível no ambiente cultivo foi favorável ao crescimento das ostras.

3. O cultivo das ostras na Lagoa do Roteiro pode ser melhorado optando-se por períodos e/ou

Tropical Oceanography, Recife, v. 40, n. 2, p. 296-308, 2012. 
VILAR, T. C.; TENÓRIO, D. de O.; FEITOSA, F. A. do N. Criação experimental da ostra-do-mangue Crassostrea rhizophorae (Guilding, 1828) em barra de São Miguel, Alagoas.

locais de temperaturas mais brandas, e períodos e locais com salinidades mais elevadas.

\section{REFERÊNCIAS BIBLIOGRÁFICAS}

ABBOTT. American seashells. 2. ed. New York, Van Nostrand Reinhold Company, 663p. 1974.

AECID. Projeto de desenvolvimento sustentável da pesca e aquicultura alagoana. Governo do Estado de Alagoas. 60p. 2008.

AMARAL, V. S. Estudo morfológico comparativo de espécies do gênero Crassostrea (Bivalvia: Ostreidae) do Atlântico oeste. Dissertação de Mestrado (Zoologia). Universidade de São Paulo. 99p. 2010.

CALDEIRA, G. A. Diagnóstico sócio-econômico e caracterização dos parques aquicolas das populações tradicionais do litoral do Paraná. Trabalho de Conclusão de Curso (Oceanografia), CEM-UFPR, Pontal do Sul. 2004.

COSTA, A. F. Fisioecologia da ostra-de-mangue de Pernambuco, Crassostrea rhizophorae (Guilding, 1828). Tese de Doutorado, Programa de Pós-graduação em Ciências (Biologia), Universidade de São Paulo, 75 p. 1975.

COSTA, P. F. Biologia e tecnologia para o cultivo de ostras. In: Brasil. Ministério da Marinha. Instituto Nacional de Estudos do Mar, Manual de Maricultura. Rio de Janeiro, cap. VIII, 36 p, 1975.

FAO. The State of World Fisheries and Aquaculture. 2010.

FERENCZ, F. L. Ecologia e Estrutura de uma comunidade de ostras da região entre marés no costão rochoso da Ilha das Cobras, Baía de Paranaguá, Brasil. Trabalho de Conclusão de Curso (Oceanografia), PUCPR, Curitiba. 1991.

FERNANDES, L. M. B. Aspectos fiso-ecológicos do cultivo da ostra-do-mangue Crassostrea rhizophorae (Guilding, 1828). Influência da Salinidade. Tese de Doutorado, USP, São Paulo, 1975.

GALTSOFF, P. S. The american oyster, Crassostrea virginica (Gmelin). Fishery. Bull. Nat. Mar. Fish. Serv., v. 64, p.1-430. 1964.

GOSLING, Elizabeth. Bivalve molluscs: biology, ecology and culture. $1^{\text {a }}$ ed. Oxford: Fishing New Books, 443p. 2003.

HONORATO DA SILVA, M.; et al. Distribuição espacial e sazonal da biomassa fitiplanctônica e dos parâmetros hidrológicos no estuário do rio Formoso (Rio Formoso, Pernambuco, Brazil). Tropical Oceanography (Online), Recife, v. 32, n. 1, p. 89-106, 2004.

IBAMA. Instituto Brasileiro do Meio Ambiente e dos Recursos Naturais Renováveis. Diretoria de Fauna e Recursos Pesqueiros. Estatística da Pesca, 108p. 2005.

IBAMA. Instituto Brasileiro do Meio Ambiente e dos Recursos Naturais Renováveis. Programa de Revitalização da Bacia Hidrográfica do Rio São Francisco - Estatística de desembarque pesqueiro - Censo estrutural da pesca 2006 - Relatório Final. Brasília (DF): 194p. 2007.

IGNÁCIO, B. L.; et al. Genetic evidence of the presence of two espécies of Crassostrea (Bivalvia: Ostreidae) on the coast of Brazil. Marine Biology, n. 136, p. 987-991, 2000.

IRIGOIEN, X.; J. CASTEL. Light limitation and distribution of chlorophyll pigments in a highly turbid estuary: The Gironde (SW France). Estuarine, Coastal shelf Sci., v. 44, p. 507-517. 1997.

LAZOSKI, C. Sistemática molecular e genética populacional de ostras brasileiras (Crassostrea spp.). Tese de Doutorado - Universidade Federal do Rio de Janeiro. 145p. Rio de Janeiro, 2004.

LEHMAN, P. W. Environmental factors associated with long term changes in chlorophyll concentration in the Sacramento - San Joaquin delta and Suisun bay, California. Estuaries 15, 335-348. 1992

LOPES, G. R. Crescimento da ostra-do-mangue Crassostrea brasiliana (LAMARCK, 1819) cultivada em dois ambientes no estado de Santa Catarina. Dissertação de mestrado

(Aquicultura). CCA-UFSC. Santa Cataria. 2010. 
VILAR,T. C.; TENÓRIO, D. O.; FEITOSA, F. A. N. Criação experimental da ostra-do-mangue Crassostrea rhizophorae (Guilding, 1828) em Barra de São Miguel, Alagoas.

MPA. Ministério da Pesca e Aquicultura. Boletim Estatístico da Pesca e Aquicultura, 20082009. 100p. 2009.

MPA. Ministério da Pesca e Aquicultura. Cultivo de Ostras. in: Manuais de Maricultura. Brazilian Mariculture Linkage Program. 29p. 2005.

NASCIMENTO, I. A.; PEREIRA, S. A.; SOUZA, R. C. Determination of the optimum comercial size for the magrove oysters Crassostrea rhizophorae in Todos os Santos Bay, Brazil. Aquaculture, $v$. 20, p.1-8. 1980

PASSAVANTE, J. Z. O.; FEITOSA, F. A. N. Dinâmica da Produtividade Fitoplanctônica na Zona Costeira Marinha. In: EskinaziLeça, E.; Neumann-Leitão, S.; Costa, M.F. (Org.). Oceanografia - Um cenário tropical. Recife, UFPE. p. 353-373. 2004.

PEREIRA, O. M.; et al. Crescimento da ostra Crassostrea brasiliana semeada sobre tabuleiro em diferentes densidades na região estuarino-lagunar de Cananéia-SP $\left(25^{\circ} \mathrm{S}, 48 \mathrm{~W}^{\circ}\right)$. Boletim do Instituto de Pesca. São Paulo. v.27, n. 2. p 163 - 174. 2001.

PERILLO, G. M. E. Definition and geomorphologic classifications of estuaries. In PERILLO, G. M. E. Geomorphology and Sedimentology of Estuaries, Development in Sedimentogoly v. 35, p. 1747. Amsterdam. 1995.

POLI, C. R. Cultivo de ostras do pacífico (Crassostrea gigas, 1852). POLI et al. (Orgs) In: Aquicultura: Experiências Brasileiras. UFSC - Multitarefa editora LTDA. P 251 - 288, 2004.

PRITCHARD, D. W. What is na Estuary: Physical Viewpoint, In: Estuaries. G. H. Lauff (Ed.) American Association for the Advancemente of Science, n83, Washington D. C. 1967.

QUAYLE, D. B. Pacific Oyster Culture in British Columbia. Can. Bull. Fish. Aquat. Sci. p. 218 241. 1988.

QUINAMO, T. S. Pesca artesanal e meio ambiente em áreas de manguezais no complexo estuarino-costeiro de Itamaracá, Pernambuco: o caso de Itapissuma. Dissertação (Mestrado). UFPB. 219p. 2006

RANDALL, J. M.; DAY, J. W. Efects of river discharge and vertical circulation and aquatic primary production in a turbid Louisiana (USA) estuary. Netherlands Journal of Sea Research v. 21, p. 231-242. 1987

RIOS, Eliezer. Seashells of Brazil. 2. Ed. Rio Grande: Editora da FURG, 492p. 1994.

SIPAÚBA-TAVARES, L. H. Limnologia dos sistemas de cultivo. In: Carcinicultura de água doce. São Paulo: FUNEP. p.47-75. 1998.

STRICKLAND, J. D. H.; PARSONS, T. R. A practical handbook of seawater analysis. Bulletin Fisheries Research board of Canada, Ottawa, v. 167, p. 1 - 205, 1972

WAKAMATSU, T. A ostra de Cananéia e seu cultivo. Editora USP/SUDELPA, 141 p., São Paulo, 1973. 